\title{
Sexual and Physical Aggression Involve Different Relationship Dynamics
}

\author{
Joshua D. Wright, ${ }^{\mathrm{a}}$ Rosemary Cogan, ${ }^{\mathrm{a}}$ and Nathanael Taylor ${ }^{\mathrm{a}}$
}

\begin{abstract}
We assessed differences in relationship functioning in physically and in sexually aggressive student men and women. Fortyseven university students in beginning psychology classes completed the Bornstein Relationship Profile Test (RPT) and the Revised Conflict Tactics Scales (CTS2) for partners and for others. The RPT categorizes people on dependency-detachment and yields three subscales: Destructive Overdependence, Dysfunctional Detachment, and Healthy Dependency. The CTS2 measures both the extent of to-partner and to-other aggression and the use of physical and sexual aggression in dealing with conflict. Students who were sexually aggressive toward partners and/or others had lower scores on Bornstein's Healthy Dependence scale than those who were not sexually aggressive, $\mathrm{F}(1,43)=6.57, \mathrm{p}=0.01$.
\end{abstract}

Keywords: Conflict Tactics Scale, physical aggression, sexual aggression, partners, Bornstein Relationship Profile Test

\section{Introduction}

Physical and sexual aggressions are common among university students (Hines and Saudino, 2003) and are directed to partners, others, or both. Some differences have been found in the interpersonal dynamics of men and women who are physically aggressive toward partners. Insecure attachment has been found as one of the more prominent characteristics involved in relationship violence and is problematic among both men and women who are aggressive toward their partners (Dutton, Saunders, Bartholomew, 1994; Cogan, Porcerelli, Dromgoole, 2001). Insecure attachment is characterized by inflexible and maladaptive dependency, clinging behavior, and the inability to cultivate affiliative ties due to low self-worth and interpersonal distrust (Bornstein et al., 2003; Schmitt, 2005). While insecure attachment is considered by some to be a precursor to aggression toward partners, it is not clear what relationship patterns are related to physical vs. sexual aggression (Blatt \& Homann, 1992; Roberts \& Noller, 1998) Bornstein (2003)'s Relationship Profile Test (RPT) assesses three kinds of relationship problems. Destructive Overdependence is a maladaptive, inflexible dependency with strong patterns of insecure clinging behavior (Bornstein, 2003), not unlike insecure attachment. Bornstein's (2003) self-report measure also includes a scale of Dysfunctional Detachment, characterized by problems in forming close relationships, and a scale of Healthy Dependency characterized by trust and confidence in relationships.

Insecure attachment can be a precursor to aggression toward partners (Dutton, Saunders, Starzomski, \& Bartholomew, 1994; Roberts and Noller, 1998). The relationship between relationship styles and aggression toward non-partners has not been considered often in studies of college students. The current study will consider attachment characteristics associated with physical vs. sexual aggression toward partners and/or others. Specifically, do physically violent students and sexually violent students differ in relationship functioning? Secondly, what gender differences exist in relationship functioning between men and women within these groups? We hypothesize that students who report physical or sexual aggression toward partners and/or others will score higher on the Destructive Overdependence subscale of the RPT and will score lower on the Healthy Dependency subscale (Bornstein et al, 2003).

\section{Method}

\section{Participants}

From a survey of students in a general psychology course willing to be recruited for research, 47 students who had been in a relationship with a partner in the past year were recruited to participate in the present study. The students ranged in age from 17 to 25 and included 27 Freshmen, 14 Sophomore, 3 Junior, and 5 Senior students.

Physical aggression was reported by 13 of the 19 men (68.4\%), often to non-partners, and 19 of the 28 women (60.7\% of women), often to both partners and non-partners. Sexual aggression was reported by 9 of the men $(47.4 \%)$, often to both partners and non-partners, and 4 of the women (14.2\%), often to both partners and non-partners.

\section{Procedure}

In small groups, students completed a number of measures, in counterbalanced order.

\section{Measures}

Students completed a brief demographic measure and responded to the CTS2 (Strauss, Hamby, Boney-McCoy, \& Sugarman, 1966) and the Relationship Profile Test (Bornstein, 2003), described below. Responses range from 1 (Not at all true of me) to 5 (very much true of me).

The Revised Conflict Tactics Scale (CTS2; Straus, Hamby, Boney-McCoy, \& Sugarman, 1996) includes 66items to assess psychological aggression ("I insulted or swore at my partner"), physical aggression ("I pushed or shoved my partner"), and sexual aggression ("I made my partner have sex without a condom") as ways of dealing with interpersonal conflict. We included the CTS2 toward partners and the CTS2 toward others. Responses range from 0 ("This has never happened") to 6 ("More than 20 times in the past year"). We 
scored responses of 7 ("Not in the past year, but it did happen before") as 0 .

The Bornstein Relationship Profile Test (RPT; Bornstein et al., 2003) is a 30-item measure with three subscales: Destructive Overdependence ("I sometimes agree with things I don't really believe so people will like me"), Dysfunctional Detachment ("When things aren't going right, I try to hide my feelings and be strong"), and Healthy Dependency ("It is easy for me to trust people").

Analyses

We carried out a multivariate analysis of variance test to compare the RPT scores of men and women who reported some or no physical aggression toward others. We also carried out a multivariate analysis of variance test to compare the RPT scores of men and women who reported some or no sexual aggression toward others.

\section{Results}

Students who were sexually aggressive had lower scores on Healthy Dependency than those who were not sexually aggressive, $\mathrm{F}(1,43)=6.57, p=.01$. Students who were physically aggressive did not differ significantly in RPT scores from students who were not physically aggressive, $\mathrm{F}(1,43)=2.90, p=.10$. The differences between student men and women and interaction between sex and groups were not statistically significant.

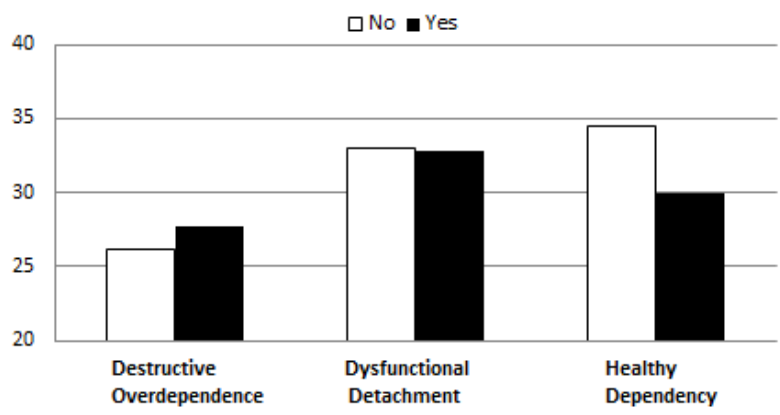

Figure 1: Relationship Profile Test scores of people who do and do not commit sexual aggression toward their partners and/or others.

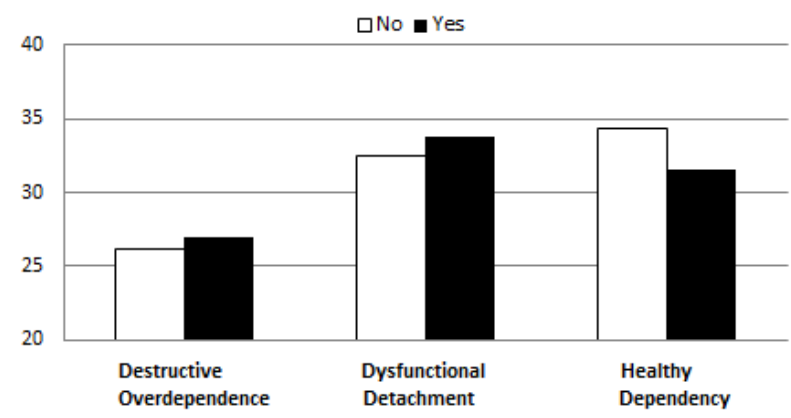

Figure 2: Relationship Profile Test scores of people who do and do not commit physical aggression toward their partners and/or others.

\section{Discussion}

As hypothesized, students who were sexually aggressive had lower scores on Healthy Dependency than those who were not sexually aggressive. Students who were sexually aggressive had lower scores on items 24 ("I don't worry about how other people see me") and 25 ("Most of my relationships involve give-and-take, with both people contributing their share"). Students who were physically aggressive did not differ in RPT scores as compared to students who were not physically aggressive, which surprised us.

However, the finding that there are differences in the relationship dynamics associated with sexual vs. physical aggression toward others may be helpful in future work. More work is necessary - as is usually the case - and a larger sample will make it more possible to untangle the dynamics of physical and sexual abuse toward partners and toward nonpartners.

\section{References}

Bornstein, R. F., Huprich, S. K. (2006). Construct validity of the relationship profile test: Three-year retest reliability and links with core personality traits, object relations, and interpersonal problems. Journal of Personality Assessment, $86(2), 162-171$.

Bornstein, R. F., Languirand, M. A., Geiselman, K. J., Creighton, J. A., West, M.A., Gallagher, H. A., \& Eisenhart, E. A. (2003). Construct validity of the relationship profile test: A self-report measure of dependency-detachment. Journal of Personality Assessment, 80(1), 64-74.

Cogan, R, \& Ballinger III, B. C. (2006). Alcohol problems and the differentiation of partner, stranger, and general violence. Journal of Interpersonal Violence, 21(7), 1-12.

Cogan, R., Porcerelli, J. H., \& Dromgoole, K. (2001). Psychodynamics of partner, stranger, and generally violent male college students. Psychoanalytic Psychology, 18(3), 515-533.

Dutton, D. G., Saunders, K., Starzomski, A., \& Bartholomew, K. (1994). Intimacy-anger and insecure attachment as precursors of abuse in intimate relationships. Journal of Applied Social Psychology, 24, 1367-1386.

Haggerty, G., Blake, M., Siefert, C. J. (2010). Convergent and divergent validity of the relationship profile test: Investigating the relationship with attachment, interpersonal distress, and psychological health. Journal of Clinical Psychology, 66(4), 339-354.

Hines, D. A., \& Saudino, K. J. (2003). Gender differences in psychological, physical, and sexual aggression among college students using the Revised Conflict Tactics Scale. Violence and Victims, 18(2), 197-217.

Roberts, N., \& Noller, P. (1998). The associations between adult attachment and couple violence: The role of communication patterns and relationship satisfaction. In Jeffry Simpson and William S. Rholes (Eds.), Attachment Theory and Close Relationships (pp. 317-350). New York: Guilford Press.

Schmitt, D. P. (2005). Is short-term mating the maladaptive result of insecure attachment? A test of competing evolutionary perspectives. Personality and Social Psychology Bulletin, 31(6), 747-768.

Straus, M. A., Hamby, Sherry L., Boney-McCoy, S., \& Sugarman, D. B. (1996). The Revised Conflict Tactics Scales (CTS2): Developmental and preliminary psychometric data. Journal of Family Issues, 17(3), 283316. 